http://doi.org/10.48195/sepe2021-053

\title{
PROFILAXIA PRÉ- EXPOSIÇÃO AO HIV NO SISTEMA ÚNICO DE SAÚDE: RELATO DE EXPERIÊNCIA
}

\section{Elizangela Freo Ruviaro1; Andressa Soares Azambuja ${ }^{2}$ Fabiana Porto da Silva ${ }^{3}$}

\section{RESUMO}

Este trabalho tem como objetivo informar sobre a Profilaxia Pré-Exposição ao vírus da imunodeficiência humana-HIV (PrEP) no Sistema Único de Saúde (SUS). Constitui-se como relato de experiência, realizado nos meses de fevereiro a setembro de 2021, a partir da vivência em um serviço especializado localizado na região central do estado do Rio Grande do Sul. Foi realizado previamente leitura dos artigos relacionados com o tema. Após, ocorreu a escrita do relato de experiência, relacionando a vivência dos residentes, com as evidências da leiteratura. Contudo, foi possível observar que as populações chaves e prioritárias não buscam o serviço por motivos como, não aceitarem sua condição, vergonha, não querer ter compromisso em comparecer nas consultas e exames de rotina, dentre outras situações. Conclui-se que é importante realizar ações educativas, para levar o conhecimento para toda população chave que pode fazer uso da PrEP, desse modo reduzindo o número de infecções pelo vírus da imunodeficiência humana.

Palavras-chave: Antirretrovirais; Estratégia; População-chave.

Eixo Temático: Atenção Integral e Promoção à Saúde (AIPS)

\section{INTRODUÇÃO}

Durante o acompanhamento nesse serviço especializado foi percebido que a maioria dos usuários da PrEP são homossexuais. Frente a isso, se deparamos com uma grande dificuldade, que é agregar toda população chave e prioritária que necessita dessa prevenção, pois são as que são consideradas mais expostas ao vírus da imunodeficiência humana. Nosso grande desafio, é levar o conhecimento

\footnotetext{
${ }^{1}$ Elizangela Freo Ruviaro - Universidade Franciscana- elizfreo@yahoo.com.br

${ }^{2}$ Andressa Soares Azambuja - Universidade FranciscanaAndressa.azambuja530@gmail.com

${ }^{3}$ Fabiana Porto da Silva - Universidade Franciscana- fabiana.silva@ufn.com.br
} 
para todas essas pessoas consideradas mais vulneráveis e não somente para os homossexuais.

Por isso é de fundamental relevância para compreender o Sistema Único de Saúde, intender do que se trata a Lei 8080/90, que compreende os princípios de universalidade, integralidade e participação da comunidade, ou seja, toda população tem direito a qualidade e assistência à saúde. Mediante a isso, é possível garantir um atendimento aos todos os usuários (TONDO, PINTO, RODRIGUES, 2021).

Além disso, é indispensável contextualizar sobre as políticas públicas no serviço especializado. Logo, é importante destacar que o Programa Municipal de Prevenção e Controle das Infecções Sexualmente Transmissíveis (ISTs), Síndrome da Imunodeficiência Adquirida (Aids) e Hepatites Virais está diretamente relacionado com a Atenção Secundária e Vigilância da Saúde. Busca implantar políticas públicas visando realizar estratégias de prevenção, promoção tratamento das ISTs, oferece atendimento integral e igualitário para toda a demanda espontânea. Como ferramenta para fazer isso, são ofertadas capacitações, distribuição de materiais informativos, bem como, distribuição de preservativos masculino, feminino, gel lubrificantes e conta com uma farmácia especializada para atender todos os usuários (BRASIL, 2020).

Anteriormente, o HIV era conhecido pela população como um vírus gay, pois, - escritor Caio Fernando de Abreu, criador da obra dama da noite era um homossexual assumido, falecendo por diversas complicações relacionadas ao vírus, sendo que as células da imunidade são afetadas, assim deixando a pessoa mais suscetível a contrair outras doenças e consequentemente levando ao óbito (BARP, MITJAVILA, 2020).

Com o avanço das pesquisas, é possível prevenir contra o vírus, sendo que as formas de prevenção, pode ser utilizada a prevenção combinada conhecida como a Profilaxia Pré-Exposição (PrEP). A PrEP é definida como uma estratégia de prevenção combinada da infecção pelo HIV, ou seja, com o uso dessa medicação o organismo se prepara, caso tenha uma exposição de risco ao HIV não se infectando nesse momento. Ela é composta por duas medicações (tenofovir +entricitabina) que deve ser ingerida via oral diariamente de uso contínuo. Lembrando, que para 
questões de cuidado a pessoa que utilizar deve se fazer o acompanhamento, a fim de evitar algum dano na função renal e hepática (BRASIL, 2018).

Entratanto essa estratégia de prevenção combinada está liberada apenas para a população chave e prioritária, ou seja, para aquelas pessoas que tem o risco aumentado para contrair o vírus. São consideradas como público alvo: homossexuais e outros homens que fazem sexo com homens $(\mathrm{HSH})$, pessoas transexuais, trabalhadores (as) do sexo, bem como, quem não faz uso de preservativo constantemente, que se relaciona com uma pessoa que que é portadora do HIV e não faz tratamento, que frequentemente trata outras ISTs e quem utiliza com pouco intervalo de tempo a Profilaxia Pós- Exposição conhecida como a PEP (ORGANIZAÇÃO PAN- AMERICANA DA SAÚDE, 2017).

Logo, se faz necessário estudar a PrEP porque essa prevenção combinada ao HIV, foi inserida no SUS recentemente e uma boa parte da população desconhece tal prevenção. Com esse intuito ela foi implementada como um antirretroviral para aquelas pessoas que ainda não se infectaram pelo vírus do HIV. No entanto, essa estratégia de prevenção não pode ser utilizada por toda população, ela está indicada apenas por aquelas pessoas que se expõem mais ao vírus do HIV, ou seja, pela chamada população chave e prioritária (BRASIL, 2020).

É extremamente importante salientar também que essa medicação só previne o HIV, por este motivo é indispensável o uso do preservativo em todas as relações, orais, sexuais e anais, a fim de, se prevenir contra as demais Infecções Sexualmente Transmissíveis (ISTs) e promover a redução de danos, transmissão vertical, bem como, diminuir a incidência de casos de contaminação pelo vírus do HIV (BRASIL,2018).

Diante do exposto, o artigo tem como objetivo geral informar sobre a Profilaxia Pré-Exposição ao HIV (PrEP) no Sistema Único de Saúde (SUS).

\section{METODOLOGIA}

Constitui-se como relato de experiência, realizado nos meses de fevereiro a setembro de 2021, a partir da vivência em um serviço especializado localizado na região central do estado do Rio Grande do Sul. Foi realizado previamente leitura dos 
artigos relacionados com o tema. Após, ocorreu a escrita do relato de experiência, relacionando a vivência dos residentes, com as evidências da leiteratura. Os residentes fazem parte do Programa de Residência Multiprofissional em Atenção Clínica Especializada com Ênfase em Infectologia e Neurologia da Universidade Franciscana.

O serviço especializado trata pessoas que vivem com HIV e Hepatites Virais, setor de testagem rápida e aconselhamento sobre as Infecções Sexualmente Transmissíveis (ISTs). Também conta com uma Unidade de Dispensação de medicamentos (UDM), com horário de funcionamento de segunda a sexta-feira, das 07:30 às 12:00 e das 13:00 às 16:30 hora, sendo nas quartas-feiras pelo período da manhã, a partir das 09:30 é fechada por causa da reunião de equipe de saúde e sempre no primeiro dia útil é fechada para fazer o balanço mensal.

A equipe de saúde, é composta por uma enfermeira, uma psicóloga, uma assistente social, uma técnica de enfermagem, uma auxiliar de laboratório, uma assistente administrativa, um médico dermatologista, quatro infectologistas, duas farmacêuticas, uma recepcionista, uma auxiliar de serviços gerais, 4 residentes, sendo dois psicólogos e duas enfermeiras, além dos acadêmicos de enfermagem e psicologia.

Quanto a estrutura do estabelecimento, contém uma sala da enfermagem, uma recepção, uma sala de espera, três salas de atendimento, uma sala de procedimentos da enfermagem, uma sala de reuniões, uma sala de atendimento psicológico, uma sala de uso exclusivo para a assistente social, um almoxarifado, uma cozinha e três banheiros, sendo que um é para os usuários do serviço.

Segundo Gil (2017), a pesquisa exploratória é definida como aquela que busca estudar algo que foi pouco divulgado e que merece ser aprofundado por ser algo recente. Já a pesquisa pesquisa bibliográfica é uma pesquisa que é realizada através de materiais já publicados.

A pesquisa qualitativa é aquela que é utilizada para estudar sobre algo que é pouco conhecido e divulgado, que é a PrEP (POUPART, 2008).

Frente a isso, este relato de experiência utilizou como coleta de dados a Biblioteca Virtual em Saúde (BVS), a base de dados Literatura Latino-Americana e 
do Caribe em Ciências da Saúde (LILACS) e protocolos do Ministério da Saúde. Para a elaboração da estratégia de busca foram utilizados como descritores de assunto: "HIV" OR Profilaxia Pré-Exposição" OR "Estratégia".

Para os critérios de inclusão, foram estabelecidos artigos, protocolos no idioma português que estivessem disponiveis gratuitamente. Como critérios de exclusão, foram excluídos produções que se repetiam e que fugiam do tema proposto. Foram adotados os critérios de citação de dados de acordo com o padrão fornecido pelas normas da Associação Brasileira das Normas Técnicas (ABNT) e da Lei 9610 dos Direitos Autoriais.

\section{RESULTADOS E DISCUSSÕES}

A prevalência do HIV na população brasileira em 2014 era 0,4\% tendo como faixa etária entre homens e mulheres entre 15 a 49 anos. Dentre a população chave foi observado que o vírus do HIV atingiu cerca de 4,9\% em mulheres profissionais do sexo, $5,9 \%$ em gays e HSH, 31,2\% entre pessoas transexuais, $5 \%$ em usuários de crack e outras drogas e $8 \%$ em homens e mulheres (BRASIL,2017a).

Todavia, já faz mais de 30 anos que o Brasil teve seus primeiros casos confirmados da Síndrome da Imunodeficiência Adquirida (AIDS), nesse período muitas pessoas morriam porque não se tinha muito conhecimento. Hoje em dia, é sabido que com a implementação das políticas públicas inseridas no Sistema Único de Saúde (SUS), além de ter como se prevenir contra o vírus do HIV, as pessoas têm uma vida diária com tratamento eficaz e passa a não ser mais vista como uma doença que leva a morte (BARP, MITJAVILA,2020).

Contudo, os hábitos das pessoas mudam, ou seja, talvez as pessoas que hoje se enquadrem nessa população chave, futuramente deixe de fazer parte. Em outras palavras, a PrEP não precisa ser utilizada pelo resto da vida do usuário, mas devese sempre comunicar o médico infectologista sobre sua decisão de parar. Portanto, a medicação só começa a fazer efeito a partir de sete dias de uso para relações anais e vinte dias para relações sexuais, por isso, é extremamente orientar e reforçar ao usuário sobre o uso de preservativos, até a medicação começar a fazer 
efeito. Caso, se expor ao vírus antes desse período é indicado utilizar a estratégia de prevenção PEP (ORGANIZAÇÃO PAN- AMERICANA DA SAÚDE, 2017).

Segundo Brasil (2018), é observada na mandala da prevenção combinada ao HIV, cuja ferramenta é utilizada para descrever algumas estratégias de prevenção combinada, além da PrEP descrita anteriormente, pode-se também utilizar a Profilaxia Pós-Exposição (PEP) quando houver alguma exposição de risco, lembrando que a mesma somente pode ser utilizada até setenta e duas horas após o ocorrido.

Além disso, também se destaca a importância de impedir a transmissão vertical, ou seja, evitar a transmissão durante a gestação, parto e amamentação. Nas situações em que a gestação é programada e a gestante está fazendo o tratamento reduz em menos de $2 \%$ de contrair o vírus. Já para aquelas que não houve planejamento e não tem boa adesão ao tratamento o risco varia de 15 a 45\%, ou seja, há um risco aumentado para ocorrer a transmissão vertical (BRASIL, 2019a).

Outra prevenção é estar em dia com as vacinações da hepatite B e HPV. É fundamental realizar a imunização para a hepatite $B$ em meninas e mulheres de 10 a 49 anos. No pré-natal as ações de prevenção começam desde a testagem para as Infecções Sexualmente Transmissíveis e posteriormente realizada administração de imunoglobulina no recém-nascido. Essas medidas de prevenção vertical são importantes para reduzir a transmissão vertical e todas estão disponíveis no SUS (BRASIL, 2019b).

Ainda mais, deve-se tratar e fazer diagnóstico das Infecções Sexualmente Transmissíveis, usar preservativo feminino, masculino, gel lubrificante, fazer testagem regular e tratar todas as pessoas que forem descobertas com HIV/ Aids. Todas essas formas de prevenção, tem como finalidade promover uma prevenção combinada do HIV, que é uma estratégia de prevenção que abrange diversas barreiras, reduzindo o número de infecção pelo vírus do HIV (BRASIL,2017b).

Logo, utilizando todas essas estratégias contra o HIV, acarretará na redução do contágio pelo vírus. Vale lembrar que para a medicação da PrEP ser considerada eficaz a mesma deve ser tomada todos os dias no mesmo horário. Se faz necessário 
realizar exames de acompanhamento e comparecer nas consultas, pois, em alguns casos pode acontecer que com o tempo os antirretrovirais façam mal para a função renal, hepática e até mesmo na densidade mineral. Quanto isto acontece é indicado parar de tomar o antirretroviral e posteriormente a pessoa irá melhorar dessas complicações (BARP, MITJAVILA,2020).

Diante disso, é visível que se não houvesse a PrEP, iria ter uma incidência maior de casos de infecção pelo vírus do HIV e com isso ao longo do uso contínuo dos antirretrovirais, pode criar uma resistência a medicação. Entretanto, é esperado que a resistência da PrEP seja bem menor que o índice de casos de HIV não controlado (BRASIL, 2020).

Portanto, informar sobre a PrEP é fundamental as pessoas, independente de suas atividades diárias, buscando reduzir os riscos de infectados e infecções pelo vírus. Com isso, o serviço de saúde especializado se torna essencial, frente a todo a sociedade, onde o fortalecimento do SUS deve ser cada mais reforçado, em todo território nacional.

\section{CONCLUSÃO}

Percebe-se que a PrEP é de suma importância para evitar a transmissão da infecção pelo vírus do HIV na população mais vulnerável, bem como não ocorrer a transmissão vertical.

Com a implementação da PrEP, as pessoas não são rotuladas como uma pessoa doente, bem como, quebrando esse tabu que era somente a população homossexual que estava associada com a doença da AIDS. Como foi observado nesse estudo, o antirretroviral é considerado quase cem por cento seguro, basta fazer ser uso correto, respeitar os horários da ingesta e fazer o acompanhamento necessário, afim de, não causar nenhum dano seu organismo.

Entretanto, observa-se que com a inserção da PrEP houve uma redução dos casos de infecção pelo vírus do HIV, da doença AIDS e também ajudou na redução de danos, ou seja, diminuiu a transmissão vertical e a evolução para o quadro mais grave, que é quando se desenvolve a doença. Tal estratégia de prevenção 
combinada fez com que as pessoas apresentem uma relação sexual mais segura e saudável.

\section{AGRADECIMENTOS}

Agradeço a Deus por me guiar, sou extremamente grata pela ajuda prestimosa de minha orientadora Fabiana, pela paciência, carinho e que soube me encaminhar nos estudos e pela minha família e colegas, que me apoiaram e estimularam a fazer este artigo.

\section{REFERÊNCIAS}

BARP, Luiz Fernando Greiner; MITJAVILA, Myriam Raquel. O reaparecimento da homossexualidade masculina nas estratégias de prevenção da infecção por HIV: reflexões sobre a implementação da PrEP no Brasil. Revista de Saúde Coletiva, Rio de Janeiro, v. (30),2020.

BRASIL. Ministério da Saúde. Boletim Epidemiológico: Hepatites Virais 2019. Brasília-DF. Volume 50, № 17, jul. 2019a.

BRASIL. Ministério da Saúde. Prevenção combinada do HIV: Bases Conceituais para profissionais trabalhadores (as) e gestores (as) de saúde. Secretaria de Vigilância em Saúde Departamento de Vigilância, Prevenção e Controle das Infecções Sexualmente Transmissíveis, do HIV/Aids e das Hepatites Virais. BrasíliaDF,2017a.

BRASIL. Ministério da saúde. Protocolo Clínico e Diretrizes Terapêuticas para a Profilaxia Pré-Exposição (PrEP) de risco a Infecção pelo HIV. Brasília, DF, 2018.

BRASIL. Ministério da Saúde. Protocolo Clínico e Diretrizes Terapêuticas para a Prevenção da Transmissão Vertical de HIV, sífilis e Hepatites Virais. BrasíliaDF, 2019b. 
BRASIL. Ministério da saúde. Protocolo e Controle Das IST, Aids e Hepatites Virais- Serviço de Assistência Especializada-SAE e Centro de Testagem e Aconselhamento. Ponta Grossa, 2020.

BRASIL. Ministério da saúde. Tenofovir associado a entricitabina (TDF/ FTC $300 / 200 \mathrm{mg}$ ) como profilaxia Pré-Exposição (PrEP) para populações sob maior risco de adquirir o vírus da imunodeficiência humana (HIV). Relatório de Recomendação. Secretaria de Ciência, Tecnologia e Insumos Estratégicos Esplanada dos Ministérios, Bloco G, Edifício Sede, $8^{\circ}$ andar, Brasília- DF maio,2017b.

GIL, Antônio Carlos. Como elaborar projetos de pesquisa . 5 ed. Ex.4 editora atlas S.A., São Paulo, 2017.

ORGANIZAÇÃO PAN- AMERICANA DA SAÚDE (OPAS). Ministério da Saúde. Ferramenta da OMS para a implementação da Profilaxia Pré- Exposição (PrEP) ao HIV. Estados Unidos de América, julho de 2017.

POUPART, Jean et al. A Pesquisa qualitativa: Enfoques epistemológicos e metodológicos. Petropólis-RJ,2008.

TONDO, Jackeline Rocha; PINTO, Kauê Antunes; RODRIGUES, Gabriela Meira de Moura. Qualidade do atendimento na atenção primária do Sistema Único de Saúde: revisão bibliográfica. Revista Liberum Accessum .9(3):19-29, maio, Luziânia, Brasil, 2021. 